\title{
PENERAPAN BACKPROPAGATION DALAM MEMPREDIKSI PRODUKSI KELAPA SAWIT UNIT KEBUN MARJANDI
}

\author{
Azlan Zulhamsyah ${ }^{1}$, Saifullah², Muhammad Ridwan Lubis ${ }^{3}$ \\ ${ }^{1}$ Mahasiswa Program Studi Sistem Informasi STIKOM Tunas Bangsa Pematang Siantar \\ ${ }^{2}$ STIKOM Tunas Bangsa Pematangsiantar, Indonesia \\ ${ }^{3}$ AMIK Tunas Bangsa Pematangsiantar, Indonesia \\ Email: ${ }^{1}$ Azlanzulhamsyah97@gmail.com, ${ }^{2}$ Saifullah@amiktunasbangsa.ac.id, \\ ${ }^{2}$ M.ridwanlubis@amiktunasbangsa.ac.id
}

\begin{abstract}
Abstrak
Tanaman kelapa sawit merupakan salah satu jenis tanaman perkebunan yang menduduki posisi penting dalam sektor pertanian umumnya, dan sektor perkebunan khususnya. Hal ini disebabkan karena dari sekian banyak tananam yang menghasilkan minyak atau lemak. Produksi diperoleh melalui suatu proses yang cukup panjang dan penuh resiko. Disini penulis menerapkan sebuah metode Backpropagation yang mana metode tersebut merupakan bagian dari pembelajaran terawasi yang biasanya di gunakan untuk lapisan untuk menentukan bobot-bobot yang tehubung dengan neuron-neouron yang ada pada lapisan yang tersembunyi. Yang mana metode Backpropagation tersebut akan di virtualsasika ke dalam program matlap dan akan menghasilkan perhitungan yang valid. Dari hasil pengujian data Laporan Produksi Tahun Tanam Kelapa Sawit di dapat pada arsitektur 3-8-8-1 yang menunjukan dari target dikurang dengan output jst bahwa SSE 0,02976 yang menunjukan bahwa adanya peningkatan jumlah produksi kelapa sawit sebagai target. Dari data yang didapat, bahwa perfomance perhitungan jaringan saraf tiruan dengan Algoritma Backpropagation adalah $67 \%$.
\end{abstract}

Kata Kunci: Backpropagation, Tanaman Kelapa Sawit, Produksi Kelapa Sawit, Unit Kebun Marjandi

\begin{abstract}
Oil palm plantations are one of the types of plantation crops that occupy an important position in the agricultural sector in general, and the plantation sector in particular". This is because of the many plants that produce oil or fat. Production is obtained through a process that is quite long and full of risk. Here the author applies a Backpropagation method in which the method is part of supervised learning that is usually used for layers to determine the weights associated with neurons in the hidden layer. Which Backpropagation method will be virtualized into matlap program and will produce valid calculations. From the results of testing the Palm Oil Planting Year Production Report obtained in the 3-8-8-1 architecture which shows the target is reduced by the output jst that SSE 0.02976 which shows that there is an increase in the number of palm oil production as a target. From the data obtained, that the performance calculation of artificial neural networks with Backpropagation Algorithm is $67 \%$.
\end{abstract}

Keywords: Backpropagation, Oil Palm Plantations, Palm Oil Production, The Marjandi Garden Unit

\section{PENDAHULUAN}

Kelapa sawit salah satu komoditas ekspor perkebunan terbesar di Indonesia karena Indonesia mempunyai struktur tanah serta curah hujan yang cocok untuk perkebunan kelapa sawit yang menghasilkan nilai ekonomi terbesar per hektarnya di dunia. Tanaman kelapa sawit merupakan salah satu jenis tanaman perkebunan yang menduduki posisi penting dalam sektor pertanian umumnya, dan sektor perkebunan khususnya". Hal ini disebabkan karena dari sekian banyak tananam yang menghasilkan minyak atau lemak. Produksi diperoleh melalui suatu proses yang cukup panjang dan penuh resiko. Panjangnya waktu yang dibutuhkan tidaklah sama, tergatung pada jenis komoditas yang diusahakan. Tidak hanya waktu, kecukupan faktor produksi pun turut sebagai penentu pencapaian produksi. keberhasilan budidaya suatu jenis komoditas tergantung pada kultivar tanaman, agroekologi/lingkungan tempat tumbuh tempat melakukan budidaya tanaman dan pengelolaan yang dilakukan oleh Badan Usaha Milik Negara (BUMN).

Sebagai tanaman yang bernilai ekonomi dan sejalan dengan peningkatan kebutuhan kelapa sawit di pasar dunia, maka pada ruang lingkup di perkebunan tiap tahunnya akan diadakan Rencana Kerja dan Anggaran Perusahaan (RKAP). Ini dilakukan untuk merencanakan target produksi dan anggaran yang akan digunakan untuk tahun berikutnya. Pada PT. Perkebunan Nusantara IV Unit Kebun Marjandi, target produksi dilakukan masih tidak maksimal dengan melihat hasil produksi tahun sebelumnya.Permasalahan yang menjadi dasar dilakukannya penelitian ini adalah bagaimana menentukan produksi Kelapa Sawit ke dalam metode Backpropagation. Sehingga didapat produksi Kelapa Sawit yang paling produktif dan tidak produktif. Tujuan yang ingin dicapai dalam penelitian ini adalah untuk menerapkan sebuah algoritma Backpropagation yang dapat digunakan untuk mengetahui apakah prediksi produksi kelapa sawit yang akan di analisa sesuai hasil dengan hasil yang di teliti dan menggunakan Data Backpropagation.

Penulis memberikan solusi untuk memprediksi produksi kelapa sawit yang menggunakan sebuah algoritma Backpropagation. Berdasarkan latar belakang di atas penulis mengangkat judul "Penerapan Backpropagation dalam Memprediksi Produksi Kelapa Sawit Unit Kebun Marjandi”. diharapkan dengan penelitian ini dapat membantu pihak Perkebunan Unit Kebun Marjandi dibagian Kantor Tanaman dan dapat membantu bagian Rencana Kerja dan Anggaran Perusahaan (RKAP) untuk meningkatkan produksi kelapa sawit Unit Kebun Marjandi. 


\section{TEORITIS}

\subsection{Algoritma Backpropagation}

Keunggulan utama dari sistem algoritma backpropagation adalah kemampuan "belajar" dari contoh yang diberikan. Backpropagation merupakan algoritma pembelajaran yang terawasi dan biasanya digunakan oleh perceptron dengan banyak layar lapisan untuk mengubah bobot-bobot yang ada pada lapisan tersembunyinya. Algoritma backpropagation adalah algoritma iteratif yang mudah dan sederhana yang biasanya berkinerja baik, bahkan dengan data yang kompleks [1].

Menurut [3] Algoritma backpropagation ditentukan oleh tiga (3) hal :

1. Pola hubungan antar neuron (disebut arsitektur jaringan).

2. Metode untuk menentukan bobot penghubung (disebut metode training/learning).

3. Fungsi aktivasi, yaitu fungsi yang digunakan untuk menentukan keluaran suatu neuron.

Backpropagation merupakan jaringan dengan lapisan jamak (multilayer network) yang memiliki ciri khas tertentu yaitu memiliki 3 jenis layer yakni input layer, hidden layer, output layer. "Backpropagation dapat menyelesaikan permasalahan yang kompleks dibandingkan dengan metode/algoritma yang lainnya". [3]. Model arsitektur backpropagation dapat dilihat pada gambar 2. berikut.

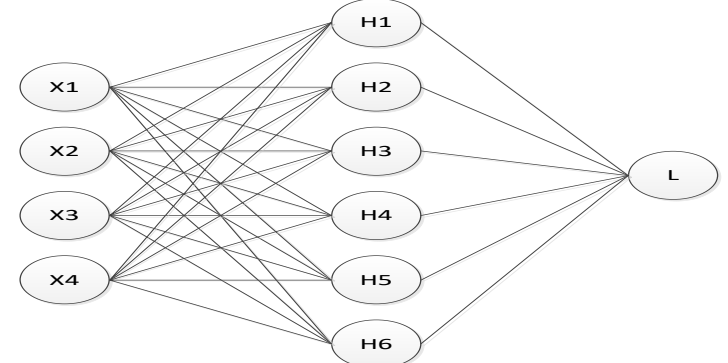

Gambar 1. Model Arsitektur Backpropagation

Keterangan :

Arsitektur jaringan yang digunakan dapat dilihat pada Gambar 2.1. yang terdiri dari tiga lapisan, yaitu : 4 lapis masukan (input), 6 lapis tersembunyi (hidden layer), dan 1 lapis keluaran (output).

1. Penyiapan data masukan dan data keluaran

Agar data dapat dikenali oleh algoritma backpropagation, maka data harus dipresentasikan ke dalam bentuk numerik antara $0 \mathrm{~s} / \mathrm{d} 1$, dimana data masukan (input) adalah data yang diperoleh dan data keluaran (output) merupakan hasil dari prediksi yang diperoleh dari model arsitektur terbaik pada saat penentuan pola terbaik. "Hal ini dikarenakan jaringan aktivasi sigmoid biner (tansig) yang rangenya dari 0 sampai 1" [4]. Proses pelatihan terawasi membutuhkan pasangan data masukan dan keluaran aktual untuk dipelajari. Data masukan dibutuhkan sebagai data masukan, dan data keluaran dibutuhkan sebagai target jaringan. "Sebelum diproses data dinormalisasi terlebih dahulu. Normalisasi terhadap data dilakukan agar keluaran jaringan sesuai dengan fungsi aktivasi yang digunakan. Data-data tersebut dinormalisasi dengan interval [0,1]" [5].

$x^{\prime}=\frac{0,8(x-a)}{b-a}+0,1$

Keterangan :

$x^{\prime} \quad$ : data yang telah ditransformasi

$x \quad$ :data yang akan dinormalisasi

$a$ : data minimun

$b$ : data maksimun

2. Pengujian algoritma backpropagation.

Pengukuran akurasi kerja jaringan dengan menggunakan data yang ada. Besarnya persentase kesalahan (\% error) dan akurasi prediksi didapatkan menggunakan persamaan berikut [5].

Persentase Kesalahan $=\left|\frac{Y_{n}-X_{n}}{Y_{n}} \times 100 \%\right|$

Keterangan :

$Y n$ : nilai sebenarnya (data sebenarnya)

$X n$ : nilai yang didapatkan (hasil prediksi)

\section{ANALISA DAN PEMBAHASAN}

\subsection{Analisa Data}

Metode penelitian terdiri atas dua metode, yaitu metode penelitian kualitatif dan metode penelitian kuantitatif. Metode penelitian kuantitatif merupakan salah satu jenis penelitian yang spesifikasinya adalah sistematis, terencana, dan terstruktur dengan jelas sejak awal hingga pembuatan desain penelitiannya, sedangkan metode penelitian kualitatif 
merupakan metode yang berlandaskan pada filsafat positifisme, serta sebagai metode artistik karena proses penelitian lebih bersifat seni (kurang terpola), dan disebut metode interpretive karena data hasil penelitian lebih berkenaan dengan intepretasi terhadap data yang ditemukan di lapangan (Syakirah, 2017).

Berdasarkan pemahaman mengenai metode penelitian kuantitatif dan metode penelitian kualitatif. Penulis dapat mengambil kesimpulan bahwa penulis menggunakan pendekatan yang dapat diselesaikan dengan komputasi numerik yaitu dengan penelitian kuantitaif yang menuntut lebih banyak terhadap terhadap penggunaan angka-angka. Berikut adalah data yang digunakan untuk memprediksi hasil kelapa sawit :

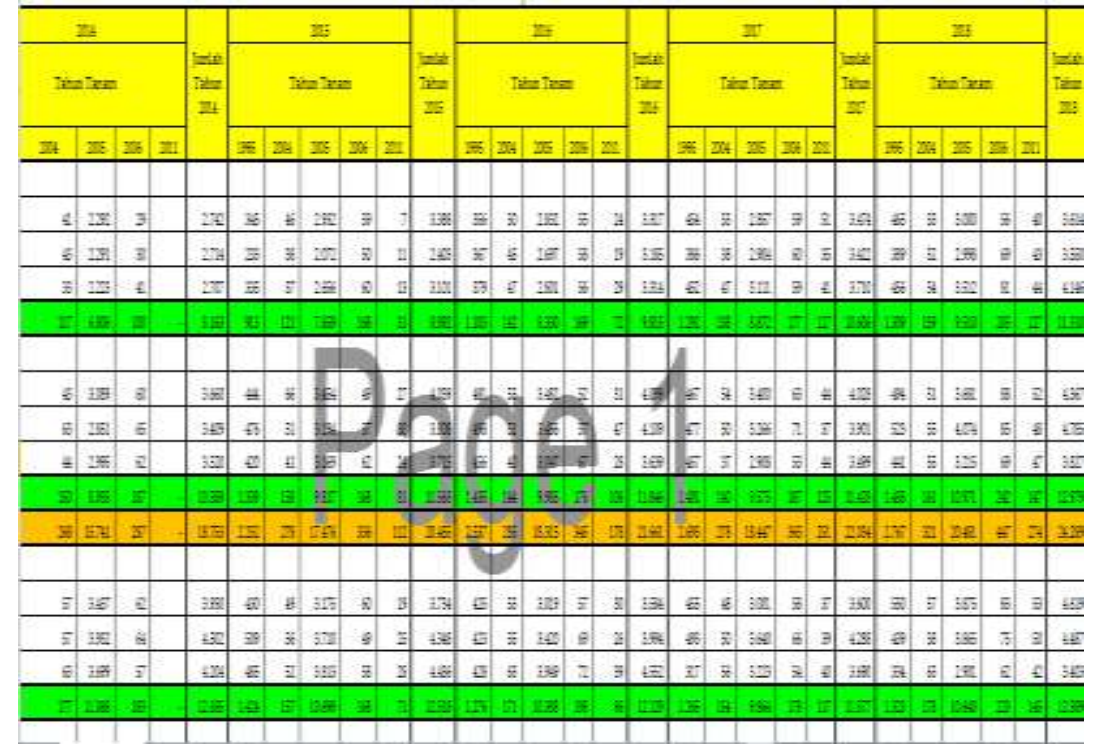

Gambar 1. Tampilan Data Produksi Pertahun

Penelitian ini memperoleh data arsip bagian kantor tanaman Unit Kebun Marjandi Tahun 2014 s/d 2018, yang di catat dalam format excel yang akan diolah untuk mendapatkan informasi yang akan di olah menggunaklan metode Backpropagation untuk memprediksi produksi kelapa sawit Unit Kebun Marjandi. Data produksi pertahun adalah kriteria yang menjadi acuan dalam pengambilan keputusan pada penilaian dengan menggunakan Jaringan Saraf Tiruan.

\subsection{Analisa Algoritma Backpropagation}

1. Pendefinisian Input

Variabel Laporan Produksi Pertahun adalah kriteria yang menjadi acuan dalam pengambilan keputusan pada penilaian dengan menggunakan Jaringan saraf tiruan. Variabel ditentukan dengan cara melihat ketergantungan data terhadap penelitian yang dilakukan. Kriteria yang digunakan adalah curah hujan, permukaan dan luas. berdasarkan hasil analisa permasalahan yang di obeservasi penulis. Adapun daftar variabel dalam memprediksi Produksi Tahun berikutnya tertera pada tabel 1 :

\begin{tabular}{|c|c|c|}
\hline No & Variabel & Nama Kriteria \\
\hline 1 & X1 & 2014 \\
\hline 2 & $\mathrm{X} 2$ & 2015 \\
\hline 3 & $\mathrm{X} 3$ & 2016 \\
\hline 4 & Target & 2017 \\
\hline
\end{tabular}

Tabel 2. Daftar Kriteria Pengujian

\begin{tabular}{ccc}
\hline No & Variabel & Nama Kriteria \\
\hline 1 & X1 & 2015 \\
2 & X2 & 2016 \\
3 & X3 & 2017 \\
4 & Target & 2018 \\
\hline
\end{tabular}

Data sampel yang digunakan adalah hasil wawancara dan observasi kepada pihak-pihak yang berkompeten pada PTPN IV Marjandi. Data ini nantinya akan ditransformasikan ke sebuah data antara 0 sampai 1 sebelum dilakukan pelatihan dan pengujian menggunakan Jaringan saraf tiruan algoritma Backpropagation dengan rujukan rumus (1).

2. Pendefinisian Target

Adapun data target adalah pada penelitian ini ialah hasil panen pada tahun sebelumnya.

3. Pendefinisian Output 
Hasil yang diharapkan pada tahap ini adalah deteksi pola menentukan nilai terbaik untuk memprediksi hasil panen pada bulan selanjutnya. Hasil pengujian adalah sebagai berikut:

a. Untuk mengetahui prediksi jumlah peningkatan jumlah hasil produksi pada tahun berikutnya tentu saja didasarkan pada hasil jumlah produksi pada tahun sebelumnya. Output dari prediksi ini adalah pola arsitektur terbaik dalam memprediksi dengan mengukur jumlah produksi pada tahun sebelumnya terhadap pada tahun berikutnya dengan melihat error minimum.

b. Kategorisasi Output pelatihan (training) dan pengujian (testing) Kategori untuk output ditentukan oleh tingkat error minimum dari target. Batasan kategori tersebut terdapat pada tabel berikut:

Tabel 3. Data Kategoris

\begin{tabular}{cccc}
\hline No & \multicolumn{2}{c}{ Keterangan } & Error Minimum \\
\hline 1 & 1 & Benar & $0,05-0,01$ \\
2 & 0 & Salah & $>0,05$ \\
\hline
\end{tabular}

4. Pengolahan Data

Pengolahan data dilakukan dengan bantuan Matlab 6.1 aplikasi perangkat lunak. Sampel Data adalah laporan produksi tahun tanam pertahunnya yang dikelompokkan berdasarkan pertahun dan bulan. Data ini akan digunakan pada data pelatihan dan data pengujian. Sampel data yang telah diproses adalah sebagai berikut.

Tabel 4. Data Laporan Produksi Tahun Tanam Kelapa Sawit

\begin{tabular}{lcccc} 
Bulan & Jumlah 2014 & Jumlah 2015 & Jumlah 2016 & Jumlah 2017 \\
\hline Januari & 2.742 & 3.388 & 3.317 & 3.474 \\
Pebruari & 2.714 & 2.403 & 3.185 & 3.422 \\
Maret & 2.707 & 3.101 & 3.314 & 3.710 \\
April & 3.660 & 4.039 & 4.099 & 4.028 \\
Mei & 3.409 & 3.808 & 4.109 & 3.901 \\
Juni & 3.520 & 3.715 & 3.639 & 3.499 \\
Juli & 3.930 & 3.734 & 3.584 & 3.600 \\
Agustis & 4.502 & 4.348 & 3.994 & 4.288 \\
September & 4.204 & 4.436 & 4.552 & 3.690 \\
Oktober & 3.908 & 4.382 & 4.577 & 3.057 \\
Nopember & 3.530 & 3.268 & 4.294 & 4.769 \\
Desember & 3.688 & 3.602 & 3.531 & 5.021 \\
Total Setahun & 42.513 & 44.224 & 46.192 & 46.458
\end{tabular}

5. Implementasi Pemerosesan Algoritma Backpropagation

a. Proses Normalisasi

Proses normalisasi merupakan suatu langkah kerja dalam mememindahkan angka dari kolom menjadi baris dan dari bilangan bulat menjadi pecahan, hal ini dilakukan agar data tadi mudah untuk dilakukan proses perkalian bobot pada matlab karna memiliki angka pecahan atau dinormalisasikan.

Untuk mentransformasikan seluruh data real tersebut, digunakan fungsi persamaan (1) sebagai berikut.:

Data awal produksi kelapa sawit : 2014-2018

Data Pelatihan (Training Data) : :2014-2017

Target Data $: 2019$

$x^{1}=\frac{0.8(22-0)}{64-0}+0.1$

Berikut adalah nilai hasil max dari hasil data traning :

Tabel 5. Hasil max

\begin{tabular}{cc}
\hline Min $(\mathrm{a}$ & 2.403 \\
\hline Max (b & 5.021 \\
b-a & 2.617
\end{tabular}

b. Proses Normalisasi Data

Sebelum proses pegolahan data dilakukan, perlu dilakukan proses penetuan masukan (Input) serta target atau hasil yang diinginkan dari proses pengolahan data, berikut data Input dan target berdasarkan data laporan produksi yang telah dikumpulkan, berikut sampel yang diambil:

Tabel 6. Data Normalisasi Training

\begin{tabular}{lcccc}
\hline Bulan & Jumlah 2014 & Jumlah 2015 & Jumlah 2017 & Target 2017 \\
\hline Januari & 0,2035 & 0,4008 & 0,3793 & 0,4272 \\
Pebruari & 0,1950 & 0,1000 & 0,3388 & 0,4114 \\
Maret & 0,1928 & 0,3133 & 0,3782 & 0,4994 \\
April & 0,4841 & 0,5999 & 0,6181 & 0,5964 \\
Mei & 0,4073 & 0,5295 & 0,6212 & 0,5577
\end{tabular}




\begin{tabular}{lllll} 
Juni & 0,4414 & 0,5010 & 0,4776 & 0,4349 \\
Juli & 0,5665 & 0,5068 & 0,4607 & 0,4657 \\
Agustis & 0,7415 & 0,6944 & 0,5861 & 0,6760 \\
September & 0,6502 & 0,7212 & 0,7566 & 0,4932 \\
Oktober & 0,5598 & 0,7047 & 0,7642 & 0,2998 \\
Nopember & 0,4442 & 0,3641 & 0,6779 & 0,8230 \\
Desember & 0,4925 & 0,4665 & 0,4447 & 0,9000 \\
\hline
\end{tabular}

Prediksi $=\frac{(\text { target } \text { prediksi }-0,1)(b-a)}{0,8}+a$

$\mathrm{D}(1.1)=(0.8 *(3.474-2.403) / 2.617)+0.1=0.4272$

Tabel 7. Data Normalisasi Testing

\begin{tabular}{lcccc}
\hline \multicolumn{1}{c}{ Bulan } & Jumlah 2015 & Jumlah 2016 & Jumlah 2017 & Target 2018 \\
\hline Januari & 0,4008 & 0,3793 & 0,4272 & 0,4700 \\
Pebruari & 0,1000 & 0,3388 & 0,4114 & 0,4505 \\
Maret & 0,3133 & 0,3782 & 0,4994 & 0,6326 \\
April & 0,5999 & 0,6181 & 0,5964 & 0,7003 \\
Mei & 0,5295 & 0,6212 & 0,5577 & 0,8278 \\
Juni & 0,5010 & 0,4776 & 0,4349 & 0,5353 \\
Juli & 0,5068 & 0,4607 & 0,4657 & 0,7772 \\
Agustis & 0,6944 & 0,5861 & 0,6760 & 0,7368 \\
September & 0,7212 & 0,7566 & 0,4932 & 0,4055 \\
Oktober & 0,7047 & 0,7642 & 0,2998 & 0,6054 \\
Nopember & 0,3641 & 0,6779 & 0,8230 & 0,4813 \\
Desember & 0,4665 & 0,4447 & 0,9000 & 0,5978 \\
\hline
\end{tabular}

c. Data Pelatihan dan Pengujian

Setelah data Input dan target di tentukan, maka langkah selanjutnya adalah menentukan data pelatihan dan pengujian, berikut data pelatihan dan pengujian :

d. Perancangan Manual Jaringan saraf tiruan

Tahap berikutnya yaitu merancang arsitektur JST backpropagation. Dalam hal ini menggunakan beberapa model jaringan multi-layer (banyak lapisan) yang digunakan untuk mendapatkan arsitektur terbaik adalah 3-81, 3-9-1, 3-8-2-1, 3-8-7-1, 3-8-8-1 dan 3-8-9-1. Model sampel arsitektur 3-8-1 dapat dilihat pada gambar dibawah ini.

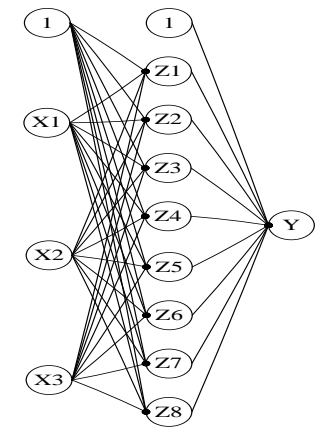

Gambar 2. Arsitektur Jaringan Backpropagation

Perhitungan manual hanya dilakukan pada sampel data Input, berikut tahapan-tahapan yang dilakukan :

1. Tahap initialitation

Tahapan dalam proses inisialisasi ini adalah menginisialisasi data Input, bobot dari Input ke pada hiden layer lalu ke output layer. Yang akan menjadi nilai Input adalah X1-Xn, dengan menggunakan :

Learning Default = 0,01 Epocs = 100.000 Goal = 0,01

Variabel Input terdiri dari

$\mathrm{X} 1=0,2035$

$\mathrm{X} 2=0,4008$

$\mathrm{X} 3=0,3793$

Berikan nilai bobot dari Input ke hidden layer. Pada tabel 7 dan 8 akan terlihat bobot dari Input layer ke hidden layer, dari hiden layer ke output yang penulis ambil dari Sistem Matlab 6.1.

Tabel 8. Bobot yang diberikan dari Input layer ke hidden layer

\begin{tabular}{llllllll}
\hline V1 & V2 & V3 & V4 & V5 & V6 & V7 & V8 \\
\hline
\end{tabular}




\begin{tabular}{ccccccccc}
\hline $\mathbf{X 1}$ & 13,0519 & $-10,9946$ & 12,0434 & $-0,5836$ & 11,0076 & 13,9496 & $-19,6360$ & $-14,1716$ \\
$\mathbf{X 2}$ & 8,2318 & $-19,9730$ & 11,4930 & 10,7355 & 10,4811 & 11,1984 & $-12,8985$ & $-2,4514$ \\
$\mathbf{X 3}$ & 16,2867 & 21,9899 & $-13,0460$ & 21,1387 & $-16,0417$ & $-10,1005$ & 18,2205 & $-18,6073$ \\
$\mathbf{1}$ & $-24,0593$ & $-21,7120$ & $-55,5020$ & $-14,9934$ & 0,2013 & $-31,4420$ & $-7,8352$ & 12,2887 \\
\hline
\end{tabular}

Tabel 9. Bobot yang Diberikan dari Hidden Layer ke Ouput Layer

\begin{tabular}{cr}
\hline & \multicolumn{1}{c}{ L } \\
\hline Z1 & $-0,7222$ \\
$\mathbf{Z 2}$ & $-0,5945$ \\
$\mathbf{Z 3}$ & $-0,6026$ \\
$\mathbf{Z 4}$ & 0,2076 \\
$\mathbf{Z 5}$ & $-0,4556$ \\
$\mathbf{Z 6}$ & $-0,6024$ \\
$\mathbf{Z 7}$ & $-0,9695$ \\
$\mathbf{Z 8}$ & 0,4936 \\
$\mathbf{1}$ & $-0,1098$ \\
\hline
\end{tabular}

Tahap 1: Perhitungan Maju:

Perhitungan maju adalah perhitungan nilai output dari unit tersembunyi atau hidden layer, sebagaimana rumus yang telah dijelaskan pada landasan teori :

$$
\begin{aligned}
Z_{\text {net } 1} & =\mathrm{V} 1+(\mathrm{X} 1 * \mathrm{~V} 11)+(\mathrm{X} 2 * \mathrm{~V} 21+(\mathrm{X} 3 * \mathrm{~V} 31) \\
& =-240,593+(130,519 * 0,2035)+(82,318 * 0,4008)+(162,867 * 0,3793) \\
& =-11,92653
\end{aligned}
$$

z_net2 $=3,1309847$

z_net3 $=-3,440869$

z_net4 $=-2,673213$

z_net5 $=3,567773$

z_net6 $=3,521685$

z_net7 $=-6,4938,5$

z_net8 $=1,364659$

Kemudian dilanjutkan dengan menghitung nilai keluaran dengan menggunakan fungsi aktivasi yang dipilih, di mana fungsi aktivasi yang digunakan adalah fungsi sigmoid biner yang mempunyai persamaan, sesuai dengan rumus pada $(2,4, a)$ :
a. $\mathrm{z} 1=\operatorname{sigmoid}[-11,92653]=\frac{1}{1+e^{(-11,92653)}}=6,61256$
b. $\mathrm{z} 1=\operatorname{sigmoid}[3,1309847]=\frac{1}{1+e^{(3,1309847)}}=0,9581529$
c. $\mathrm{z} 1=$ sigmoid $[-3,440869]=\frac{1}{1+e^{(-3,440869)}}=0,0310423$
d. $\mathrm{z} 1=\operatorname{sigmoid}[-2,673213]=\frac{1}{1+e^{(-2,673213)}}=0,0577594$
e. $\mathrm{z} 1=\operatorname{sigmoid}[3,567773]=\frac{1}{1+e^{(3,567773)}}=0,636003$
f. $\mathrm{z} 1=\operatorname{sigmoid}[3,521685]=\frac{1}{1+e^{(3,521685)}}=0,587143$
g. $\mathrm{z} 1=\operatorname{sigmoid}[-6,4938,5]=\frac{1}{1+e^{(-6,4938,5)}}=0,00151$
h. $\mathrm{z} 1=\operatorname{sigmoid}[1,364659]=\frac{1}{1+e^{(1,364659)}}=0,7965159$

Menghitung nilai output pada unit yk $(\mathrm{k}=1,2,3, \ldots, \mathrm{m})$ dengan menggunakan nilai bobot-nya, yang dijelaskan pada rumus $(2,4 \mathrm{~b})$ :

$$
\begin{aligned}
Y_{\text {ink }}= & N_{J I I} \\
= & -0,1098+(6,61256 *-0,7222)+(0,9581529 *-0,5945) \\
& +(0,0310423 *-0,6026)+(0,0577594 * 0,2076) \\
& +(0,636003 *-0,4556)+(0,587143 *-0,6024) \\
& +(0,00151 *-0,9695)+(0,7965159 *-0,1098) \\
= & -0,9379041
\end{aligned}
$$

Kemudian dihitung nilai Output dengan menggunakan fungsi aktivasi :

Tahap 2: Perhitungan Mundur:

$$
\text { sigmoid }[-0,9379041]=\frac{1}{1+e^{(-0,9379041)}}=0,2813239
$$

1. Untuk tiap unit keluaran $(y k, \mathrm{k}=1,,, \mathrm{~m})$ menerima pola target yang bersesuaian dengan pola masukan, dan kemudian dihitung informasi kesalahan Hitung faktor $\delta$ diunit keluaran berdasarkan kesalahan setiap unit keluaran $\mathrm{yk}$, rumus yang digunakan berdasarkan rujukan pada $(2,5 \mathrm{a})$ $\delta 1=(0,4272-0,2813239) * 0,2813239 *(1-0,2813239)=0,029502681$ 
2. Suku perubahan bobot Wjk dilakukan perhitungan (yang akan digunakan untuk merubah bobot Wjk) dengan laju pelatihan learning rate $\alpha=0,01$, rumus yang digunakan berdasarkan rujukun pada $(2,5 \mathrm{~b})$

$\Delta \mathrm{W} 10=0,01 * 0,0295 * 1=0,000295027$

$\Delta \mathrm{W} 11=0,01 * 0,0295 *-11,92653=-0,003519$

$\Delta \mathrm{W} 12=0,01 * 0,0295 * 3,1309847=0,0009237$

$\Delta \mathrm{W} 13=0,01 * 0,0295 *-3,440869=-0,001015$

$\Delta \mathrm{W} 14=0,01 * 0,0295 *-2,673213=-0,00082$

$\Delta \mathrm{W} 15=0,01 * 0,0295 * 3,567773=0,000165$

3. Untuk setiap $(\mathrm{Zj}, \mathrm{j}=1, \ldots, \mathrm{p})$ dihitung delta masukan yang berasal dari neuron pada layer di atasnya, berdasarkan rujukan pada $(2,6)$ :

$\delta \_$net $1=0,0295 *-0,7222=0,1061$

$\delta \_$net $2=0,0295 *-0,5945=0,5995$

$\delta \_$net $3=0,0295 *-0,6026=-0,0815$

$\delta \_$net $4=0,0295 * 0,2076=0,1061$

$\delta \_$net $5=0,0295 *-0,4556=0,5995$

4. Kemudian nilai tersebut dikalikan dengan nilai turunan dari fungsiaktivasi untuk menghitung informasi kesalahan, berdasarkan rujukan pada $(2,7)$ :

$\delta 1=-0,0213 * 6,6126 *(1-6,6126)=-1,4089$
$\delta 2=-0,0175 * 0,9582 *(1-0,9582)=-7,0326$
$\delta 3=-0,0178 * 0,0310 *(1-0310)=-5,3475$
$\delta 4=0,0061 * 0,0578 *(1-0,0578)=3,3333$
$\delta 5=-0,0134 * 0,6360 *(1-0,6360)=-3,1117$

5. Hitung koreksi nilai bobot yang kemudian digunakan untuk memperbaharui vij, berdasarkan rujukan pada $(2,8)$ :

$\Delta v 11=0,2035 * 0,2 *-1,4089=-5,73482$

$\Delta v 21=0,2035 * 0,2 *-7,0326=-2,86251$

$\Delta v 31=0,2035 * 0,2 *-5,3475=-2,17662$

$\Delta v 41=0,2035 * 0,2 * 3,3333=1,35677$

$\Delta v 51=0,2035 * 0,2 *-3,1117=-0,00013$

Perhitungan dilanjutkan, sehingga di dapatkan data sebagai berikut :

\begin{tabular}{ccccccccc}
\multicolumn{8}{c}{ Tabel 10. Koreksi Nilai Bobot } \\
\hline & V1 & V2 & V3 & V4 & V5 & V6 & V7 & V8 \\
\hline X1 & $-5,73482$ & $-2,86251$ & $-2,17662$ & 1,35677 & $-0,00013$ & $-0,00018$ & $-1,75585$ & 9,60716 \\
X2 & $-5,73482$ & $-2,86251$ & $-2,17662$ & 1,35677 & $-0,00013$ & $-0,00018$ & $-1,75585$ & 9,60716 \\
X3 & $-5,73482$ & $-2,86251$ & $-2,17662$ & 1,35677 & $-0,00013$ & $-0,00018$ & $-1,75585$ & 9,60716 \\
\hline
\end{tabular}

$\mathrm{W} 1($ baru $)=-0,7222+-0,00352=0,00254$

$\mathrm{W} 2$ (baru) $=-0,5945+0,00092=-0,00055$

$\mathrm{W} 3($ baru $)=-0,6026+-0,00102=0,00061$

$\mathrm{W} 4($ baru $)=0,2076+-0,00082=-0,00017$

W5 $($ baru $)=-0,4556+0,000165=-7,50108$

Bobot garis mengalami perubahan pada saat terhubung ke hiden layer, berdasarkan rujukan pada (2.11):

V11 $($ baru $)=-5,73482+13,0519=-7,48503 \mathrm{E}-08$

V21 (baru) $=-2,86251+-10,9946=3,14722 \mathrm{E}-04$

V31 (baru) $=-2,17662+12,0434=-2,62140 \mathrm{E}-04$

$\mathrm{V} 41$ (baru) $=1,35677+-0,5836=-7,91812 \mathrm{E}-06$

V51 (baru) $=-0,00013+11,0076=-1,39421 \mathrm{E}-03$

Tabel 11. Perubahan Bobot Akhir Pada $\mathrm{P}=1$ Dari Input Ke Hiden Layer

\begin{tabular}{lllllllll}
\hline & $\mathbf{V 1}$ & $\mathbf{V 2}$ & $\mathbf{V 3}$ & $\mathbf{1} 4$ & \multicolumn{1}{c}{ V5 } & \multicolumn{1}{c}{ V6 } & \multicolumn{1}{c}{ V7 } & V8 \\
\hline X1 & $-7,48503$ & 3,14722 & $-2,62140$ & $-7,91812$ & $-1,39421$ & $-2,44616$ & 3,44778 & $-1,36149$ \\
$\mathbf{X 2}$ & $-4,72079$ & 5,71729 & $-2,50159$ & 1,45656 & 10,4811 & $-1,96372$ & 2,26478 & $-2,35510$ \\
$\mathbf{X 3}$ & $-9,34012$ & $-6,29463$ & 2,83962 & 2,86804 & 2,03182 & 1,77119 & $-3,19924$ & $-1,78763$ \\
\hline
\end{tabular}

Tabel 12. Perubahan Bobot Akhir Pada P=1 Dari Hidden Ke Output Layer

\begin{tabular}{ll}
\hline & \multicolumn{1}{c}{$\mathbf{L}$} \\
\hline $\mathbf{Z 1}$ & 0,00254 \\
$\mathbf{Z 2}$ & $-0,00055$ \\
$\mathbf{Z 3}$ & 0,00061 \\
$\mathbf{Z 4}$ & $-0,00017$ \\
$\mathbf{Z 5}$ & $-0,00008$
\end{tabular}




$$
\begin{array}{ll}
\text { Z6 } & -0,00006 \\
\text { Z7 } & 0,00186 \\
\text { Z8 } & 0,00020 \\
\hline
\end{array}
$$

Setelah hasil perubahan bobot dan bias pada proses iterasi pertama selesai dilakukan maka akan menghasilkan nilai perubahan bobot dan bias yang baru melalui proses pelatihan, Proses pelatihan jaringan akan dilanjutkan secara berkelanjutan sampai nantinya menghasilkan nilai output dan juga nilai error yang terkecil, Untuk hasil dari iterasi pertama dari data baris pertama dari perhitungan manual berikut dengan output sebagai berikut :

$$
\begin{array}{rl}
Y_{\text {ink }}=N_{J I I} & \\
=-0 & 1098+(6,61256 *-0,7222) \\
& +(0,9581529 *-0,5945)+(0,0310423 *-0,6026) \\
& +(0,0577594 * 0,2076)+(0,636003 *-0,4556) \\
& +(0,587143 *-0,6024)+(0,00151 *-0,9695) \\
& +(0,7965159 *-0,1098) \\
=-0 & , 9379041
\end{array}
$$

Kemudian dihitung nilai Output dengan menggunakan fungsi aktivasi :

$$
\text { sigmoid }[-0,9379041]=\frac{1}{1+e^{(-0,9379041)}}=0,2813239
$$

Setelah itu hasil output jst dikurangkan dengan target untuk menghitung margin error :

Output Jst - Target

$0,2813-0,4272=-0,1459$

Setelah terlihat dari hasil nilai iterasi pertama dari data nilai pertama dengan nilai $-0,1459$ dapat menjelaskan bahwa perlu adanya pembelajaran data untuk memaksimalkan performance data yang diuji, Tidak sampai disitu saja dilakukan juga proses pengujian dengan pola yang sudah di tentukan, proses ini berguna untuk mendapatkan keakuratan antara pelatihan dan pengujian sehingga didapatkan kesimpulan prediksi yang akurat, Maka Untuk mempercepat proses dari pemecahan masalah dari penelitian ini, maka penulis menggunakan sebuah alat bantu program berupa Software Matlab 6,1, karena software Matlab 6,1 didesain dengan sedemikian rupa dengan mengadaptasi dari algoritma yang penulis gunakan pada penelitian ini.

\subsection{Pengujian Data Menggunakan Matlab 6.1}

Gambar dibawah menjelaskan bahwa hasil output dari Testing data yang sudah dilakukan oleh matlab.

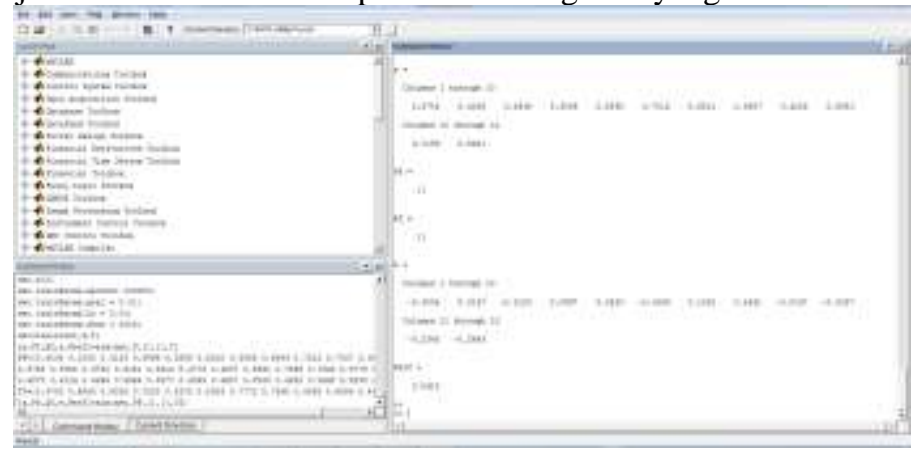

Gambar 3. Input Testing Data

Hasil percobaan menunjukkan bahwa Jaringan saraf tiruan dengan Algoritma Backpropagation yang sudah dilatih dan diuji dengan baik akan memberikan keluaran yang masuk akal jika diberi masukan yang serupa dengan pola yang dipakai untuk pelatihan dan pengujian. Sifat generalisasi ini membuat pelatihan dan pengujian lebih efisien karena tidak perlu dilakukan pada semua data. Jaringan saraf tiruan dengan Algoritma Backpropagation dibentuk dengan membuat generalisasi aturan pelatihan dan pengujian dalam model Windrow-Hooff dengan cara menambahkan lapisan tersembunyi (hidden layer). Standar Algoritma Backpropagation menggunakan algoritma penurunan gradien (gradien descent). variasi terhadap model standar dilakukan dengan mengganti algoritmanya dengan algoritma lain.

Untuk melakukan pengujian data agar memperoleh hasil prediksi yang diharapkan menggunakan model arsitektur 3-16-1 diperlukan hal sebagai berikut.

1. Data Awal/Real

Data real diperoleh dari nilai target pada data pengujian tahun 2018.

2. Target

Nilai target diperoleh dari nilai target pada normalisasi data pengujian tahun 2018 .

3. Target Prediksi 
Target prediksi diperoleh melalui software Matlab 6.1 dengan menggunakan data input yaitu data real tahun 2018 dan target adalah target tahun 2018 yang nantinya akan menghasilkan nilai data paa rentang nilai 0-1.

4. Prediksi

Prediksi merupakan hasil konversi target prediksi yang diperoleh melalui software Matlab 6.1 dengan menggunakan persamaan yang sudah ditentukan sehingga hasil yang diperoleh dapat dimengerti.

Adapun hasil prediksi produksi kelapa sawit untuk tahun 2019 dapat dilihat pada tabel 13. berikut

Tabel 13. Hasil Prediksi 2019

\begin{tabular}{lllll}
\hline No & Data Real & Target & Target Prediksi & Prediksi \\
\hline 1 & 3614 & 0,47000 & 0,64250 & 4340 \\
2 & 3550 & 0,45051 & 0,44090 & 3992 \\
3 & 4146 & 0,63264 & 0,81080 & 4630 \\
4 & 4367 & 0,70027 & 0,68110 & 4407 \\
5 & 4785 & 0,82779 & 0,64700 & 4348 \\
6 & 3827 & 0,53527 & 0,65400 & 4360 \\
7 & 4619 & 0,77721 & 0,62870 & 4316 \\
8 & 4487 & 0,73678 & 0,62190 & 4304 \\
9 & 3403 & 0,40551 & 0,37770 & 3883 \\
10 & 4057 & 0,60542 & 0,49140 & 4079 \\
11 & 3651 & 0,48133 & 0,64380 & 4342 \\
12 & 4032 & 0,59778 & 0,81440 & 4637 \\
\hline
\end{tabular}

Berdasarkan hasil prediksi yang diperoleh, jumlah produksi kelapa sawit terhitung tahun 2018 sampai dengan 2019. Dalam hal ini, algoritma backpropagation memprediksi mempunyai dua kemungkinan dimana hasil prediksi yang diperoleh merupakan hasil aktual yang dapat terjadi atau hasil prediksi yang diperoleh merupakan hasil yang kemungkinan besar tidak dapat terjadi dengan segala kelemahan algoritma backpropagation sendiri.

\section{KESIMPULAN}

Berdasarkan pembahasan sebelumnya dapat disimpulkan bahwa:

1. Penggunaan metode Backpropogation dapat di gunakan didalam penggunaan kelapa sawit PTPN IV yang mana memiliki data valid sehingga mendapatkan hasil yang sernifikat.

2. Hasil yang di dapat dari analisa metode Backpropogation dan virtualisasi mengunakan aplikasi matlab dapat di hasilkan dengan data yang valid. Dan di simpulkan bahwa metode Backpropogation dapat di jadikan sebagai metode prediksi yang sangat memudahkan untuk mencari prediksi apapun

\section{REFERENCES}

[1] L. P. Purba, A. P. Windarto, And A. Wanto, Faktor Terbesar Rendahnya Minat Ber-Kb ( Keluarga Berencana ) Dengan Metode Electre II, Pp. 369-374, 2018.

[2] H. Bartolomius And S. Palupi, Sistem Pendukung Keputusan Penerimaan Asisten Laboratorium Komputer Menggunakan Metode Simple Additive Weighting (Studi Kasus Pada Laboratorium Komputer Stmik Widya Cipta Dharma Samarinda), Pros. Semin. Ilm. Nas. Teknol. Komput. (Senatkom 2015), Vol. 1, No. Senatkom, Pp. 90-95, 2015.

[3] M. Agustin, Penggunaan Jaringan Syaraf Tiruan Backpropagation Untuk Seleksi Penerimaan Mahasiswa Baru Pada Jurusan Teknik Komputer Di Politeknik Negeri Sriwijaya, 2012.

[4] A. P. Windarto, Implementasi Jst Dalam Menentukan Kelayakan Nasabah Pinjaman Kur Pada Bank Mandiri Mikro Serbelawan Dengan Metode Backpropagation, J. Sains Komput. Inform., Vol. 1, No. 1, Pp. 12-23, 2017.

[5] C. Oktaviani And Afdal, Prediksi Curah Hujan Bulanan Menggunakan Jaringan Syaraf Tiruan Dengan Beberapa Fungsi Pelatihan Backpropagation, J. Fis. Unand, Vol. 2, No. 4, Pp. 228-237, 2013. 